\title{
Electromagnetic Sensing Techniques for Non-Destructive Diagnosis of Civil Engineering Structures
}

\author{
Massimo Bavusi et al.* \\ CNR-IMAA, \\ Italy
}

\section{Introduction}

Health Assessment Methods (HAM) and Structural Health Monitoring (SHM) aim to improve the standard of knowledge regarding the safety and maintenance of structures and infrastructure acquiring information about geometrical, mechanical and dynamical characteristics of structures. In earthquake-prone areas, this activity has the double aim of assessing the buildings structural integrity and extracting information regarding their response during a seismic event in order to define appropriate activities for risk mitigation. A number of factors afflict buildings and infrastructure safety in seismic areas:

- Outdated codes of practice: a significant number of highly urbanized areas are present globally, where a high percentage of structures have been designed and erected considering only gravity loading.

- The age of the structures and the real in-situ performance of construction material significantly affect their overall behaviour.

- Structural deficiencies such as poor material qualities and/or degradation of structural materials (rust, spalling etc.), inadequate construction detailing, low levels of ductility, brittle collapse mechanisms.

The seismic assessment of structures is performed in terms of the estimation of the earthquake intensity that would lead to a certain damage condition and/or collapse. The assessment of the seismic vulnerability of existing buildings is generally based on the knowledge of building characteristics and through a complex analysis of the possible collapse mechanisms in order to identify the most probable failure for the given structure (as example: Ansari, 2005; Douglas, 2007; Moustafa et al., 2010).

The methodological approach for the evaluation of a structure resistance is represented in Figure 1 where structural knowledge obtained through a series of test assessments is needed in order to define vulnerability and thus design suitable retrofit strategies.

\footnotetext{
${ }^{*}$ Romeo Bernini², Vincenzo Lapenna ${ }^{1}$, Antonio Loperte ${ }^{1}$, Francesco Soldovieri², Felice Carlo Ponzo ${ }^{3}$, Antonio Di Cesare ${ }^{3}$ and Rocco Ditommaso ${ }^{3}$

${ }^{1}$ CNR-IMAA, Italy

${ }^{2}$ CNR-IREA , Italy

${ }^{3}$ Basilicata University/DiSGG, Italy
} 
Since the level of reliability of the assessment method is related to the adequacy of the model and to the completeness of the information, all useful available data have to be collected in order to define the original structural characteristics such as: geometry of structural elements, characteristics and behaviour of the construction materials, presence of degradation, arrangement of longitudinal and transversal reinforcement.

The knowledge of an existing structure is never complete and the level and accuracy of construction details obviously corresponds proportionally with the available original design documentation, the time and funds available for in situ investigations and experimental tests on the structural elements.

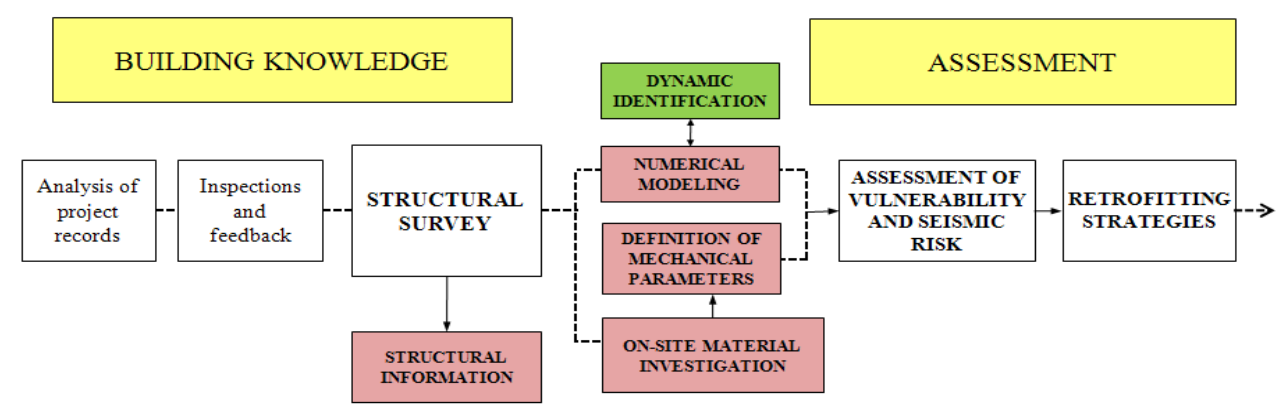

Fig. 1. Methodological approach.

A reliable assessment of the vulnerability of buildings is also strictly connected to the evaluation of the mechanical characteristics of the constitutive materials. This can be particularly complex for concrete, due to the high variability of its resistance that depends on intrinsic factors such as the composition as well as the environmental and maturing conditions, and other factors attributable to the collection technique and reworking of the concrete sample and the test conditions in general (Barlet, 1994).

A number of tests and methods have been developed for evaluating the resistance of construction materials ranging from completely non-destructive tests (NDT), where there is no damage to the structural element, using methods where the concrete surface is only slightly damaged, to partially destructive or destructive tests (DT), where the structural element has to be repaired afterwards.

The classical NDT methods, generally used for Reinforced concrete (R/C) structures, are the surface hardness method coupled with the ultrasonic method. As these methods are influenced in different and/or opposing ways by some fundamental parameters, their combined use allows outputs with minimal dispersion to be obtained. It is generally not advisable to use a single non-destructive test to estimate the strength in situ of concrete.

The range of properties that can be assessed using the range of NDT methods is significant and includes fundamental parameters such as density, elastic modulus as well as surface hardness, reinforcement location and depth of cover concrete. In some cases it is also possible to check the quality of workmanship and structural integrity through the ability to detect voids, cracking and delamination.

Preliminary tests can be performed with a covermeter according to the procedures described in the British Standard 188:204. With this technique it is possible to determine the presence and size of reinforcing bars, laps, transverse steel and depth and position of reinforcement. 
The identification of the position of the reinforcement bars is also used as a preliminary to the other NDT (such as Ultrasonic Pulse Velocity, Schmidt Rebound Hammer, Pull-out UNI EN 12504-3, 2005) and also the DT (Core Extraction and Compression Test). In addition the partially destructive method of removing the cover concrete in some areas and measuring directly the diameter and type of the reinforcement can be performed.

The Schmidt rebound hammer test is principally a surface hardness tester and is carried out according to UNI EN 12504-2 (2001). The system works on the principle that the rebound of an elastic mass depends on the hardness of the surface against which the mass impinges. There is little apparent theoretical relationship between the strength of concrete and the rebound number of the hammer, however within limits, experimental correlations are established between strength properties and the rebound number. All of this cannot be generalized and should be calibrated for each type of existing concrete, for example using the results of compression tests. In the some cases the results of the hammer tests, taken as a rebound average (Ir) is used individually to assess the homogeneity of the concrete.

The Ultrasonic test is carried out in compliance with UNI EN 12504-4 (2005) and is aimed at determining the propagation velocity of a mechanical vibration pulse in concrete. By measuring the pulse crossing time and the distance between the two probes, the apparent propagation velocity can be calculated. This value can differ from the real value when the elastic waves undergo deviations from the path identified by the conjunction line between the two probes (RILEM 1972). The factors that affect the ultrasonic test the most are linked to the concrete composition, environmental and test conditions.

When interpreting the NDT results, special attention is needed regarding the presence of possible anomalies which can negatively influence the experimental assessment of the in situ concrete mechanical characteristics. Such anomalies are generally characterized through an evident correlation of the experimental datum with either a physical parameter of reference (usually compressive strength from DT) or with respect to the trend shown by the data acquired in the same context of structural homogeneity. These anomalies usually arise from improper execution of the test or from the fact that the test is carried out in non-ideal conditions.

Direct measure of the compressive strength of concrete in a structure is provided by the Concrete Core Extraction and Compression method (DT). The process of obtaining core specimens and interpreting the strength test results is often affected by various factors that influence either the in-place strength of the concrete or the measured strength of the test specimen (UNI EN 12504-1, 2002). In spite of such disturbance factors, values measured in this way are certainly the most reliable possible. Furthermore errors can be reduced using the A.C.I. 214.4R-03 guidelines which summarize current practices for obtaining cores and interpreting core compressive strength test results.

Immediately after extraction, the core concrete is tested for carbonation (also called depassivation). Carbonation penetrates below the exposed surface of concrete extremely slowly. The significance of carbonation is that the usual protection of the reinforcing steel generally present in the concrete due to the alkaline conditions caused by the hydrated cement paste is neutralized. Thus, if the entirety of the cover concrete is carbonated, corrosion of the steel will occur if moisture and oxygen can infiltrate the section.

The necessary destruction of the test object usually makes DT methods more expensive, and these testing methods can also be inappropriate in many circumstances. Therefore the use of NDT plays a crucial role in ensuring an economical operation. A general proportion of 1 
core to 4 non-destructive investigations is recommended. Both the results from the DT and NDT are then combined in order to estimate the in situ concrete strength using the SonReb method. This method is the principal combination of Schmidt Rebound Hammer with Ultrasonic Pulse Velocity used for quality control and strength estimation of in situ concrete (Braga, 1992).

Another group of NDT methods are the Dynamic identification tests which can be used in order to assess fundamental dynamic properties (frequencies and/or modal shapes) of the structure and indirectly estimate the Young's modulus of the material (Ponzo et al., 2010). All dynamic characteristics can be estimated using two different approaches: classical methodologies based on Fourier analysis (Ditommaso et al., 2010a) or innovative methodologies based on time-frequency and interferometric analyses (Ditommaso et al., 2010b; Picozzi et al., 2011). These latter analyses are also useful to detect possible structural damage occurred after an earthquake (Ditommaso et al., 2011).

The results of the above testing methods (both NDT and DT) are used to calibrate numerical models. These models can then be compared to the likely seismic loading thus providing the overall vulnerability of the structure being considered (Ponzo et al. 2011).

Even if the methods described above can ensure (when correctly applied) a high level of structural knowledge a number of issues remain to be addressed. In order to do this innovative technologies and new methods must be developed: reduce uncertainty regarding core extraction points, improve the detection of deflection and deficiencies, detect water infiltration, improve reinforcement information, improve the depth under investigation, and reduce time and cost.

Due to rapid and flexible execution, high spatial resolution and deep investigation depth, electromagnetic sensing techniques are a group of NDT methods which can achieve these objectives. They can direct the use of classical NDT and DT methods and reduce uncertainties, coring number and the survey cost. Furthermore, their contribution to the structural knowledge allows the adoption of lower safety coefficients (through the increase in available information thus minimising spread) and thus higher calculation resistances. This in turn reduces the extent and cost of the actions required for the improvement or seismic retrofit of structures, if needed.

The building and infrastructure diagnostics can be take advantage from the use of new NDT techniques enabling larger investigation depths, spatial resolution, void and defect detection capacity, low cost and fastness. Electromagnetic sensing techniques can be an useful tool in order to achieve these objectives. They are based on injection of a form of electromagnetic energy (electrical current, radiowave, microwave, light, etc.) into the surveyed object and gathering of returned signal in order to measure electromagnetic properties (resistivity, electrical permittivity), reconstruct the inner structure, detect embedded defects.

In table 1 an overview of the advantages and disadvantages of several techniques (both classic and innovative) is presented, in terms of cost, speed of procedure, non intrusivity, accuracy of data obtained and degree of correlation with actual values.

Nevertheless, applying electromagnetic sensing techniques to man made structures, some adaptation needs to fit stringent requirements in terms of exploration depth, spatial resolution and signal/noise ratio. In fact, commonly used building materials pose challenging issues in terms of electrode impedance, coupling antennas, survey modalities, tomographic reconstruction, sensor size. 
Electromagnetic sensing techniques suitable for civil infrastructures and building diagnostic such as Ground Penetrating Radar (GPR) and Electrical Resistivity Tomography (ERT) are presented in this chapter. Concerning the GPR we focus the attention on the possibility to improve the imaging at low and radio/microwave frequencies by using novel inversion approaches such as the Microwave Tomography (MT).

Then, a novel distributed fiber optic sensor technology able to monitor strain and temperature variations, is described. Finally, we discuss about the real contribution provided by electromagnetic sensing techniques in the building and infrastructure monitoring.

\begin{tabular}{|l|c|c|c|c|c|}
\hline \multicolumn{1}{|c|}{ Test Method } & Cost & $\begin{array}{c}\text { Speed of } \\
\text { procedure }\end{array}$ & $\begin{array}{c}\text { Damage } \\
\text { effected }\end{array}$ & $\begin{array}{c}\text { Accuracy } \\
\text { of data }\end{array}$ & $\begin{array}{c}\text { Degree of } \\
\text { correlation }\end{array}$ \\
\hline Core samples & High & Slow & Moderate & Moderate & High \\
\hline Rebound hammer & Very low & Fast & None & $\begin{array}{c}\text { Only } \\
\text { surface } \\
\text { info }\end{array}$ & Low \\
\hline Ultrasonic waves & Low & Fast & None & $\begin{array}{c}\text { Complete } \\
\text { penetration }\end{array}$ & Moderate \\
\hline Covermeter & Low & Fast & None & Moderate & - \\
\hline $\begin{array}{l}\text { Electromagnetic } \\
\text { sensing }\end{array}$ & High & Moderate & None & Good & $\begin{array}{c}\text { Low/ } \\
\text { Moderate }\end{array}$ \\
\hline Dynamic Test & Low & Moderate & None & Good & None/Low \\
\hline
\end{tabular}

Table 1. Advantages and disadvantages of different health assessment techniques.

\section{Electromagnetic sensing techniques}

Electromagnetic sensing techniques use is now rather diffuse in several earth science fields such as geology, hydrogeology, seismology, glaciology, stratigraphy of urban areas study, polluted areas study, landslides characterization, etc. Few years ago, non intrusiveness and quickness of these techniques suggested their use for investigating buildings and civil engineering structures.

The migration of these techniques towards the engineering can be identified with the Microgeophysics where specific issues are the sensor miniaturizing, signal/noise ratio improvement, exploitation of all available free surfaces for energizing and acquiring signals (Cosentino et al., 2011).

Electromagnetic sensing techniques are an useful tool for the diagnostics of civil infrastructures, such as transport ones, in the framework of their static and dynamic behavior before, during and after a crisis event such as an earthquake.

In fact, they ensure a fast and not-intrusive diagnosis useful in the pre-event stage since a precautionary diagnosis of strategic buildings and transport infrastructure can be a critical issue in the seismic risk prevention.

Moreover, they can represent, during the crisis, a valid tool for the rapid damage mapping of the civil buildings and infrastructures (bridges, roads, dams, assessment) in order to have preliminary estimations of those safe for rescue forces. Then, a rapid damage assessment for private buildings enable a correct estimate of the damaged houses and resources to be 
committed. Finally, in the post-event stage, restoration interventions can be driven by the electromagnetic sensing techniques in order to minimize the costs and maximize the results. The electromagnetic sensing techniques provides information about investigated materials in terms of amplitude and phase of the gathered signals, in turn function of the electromagnetic properties of the materials.

Amongst the requirements of the infrastructure diagnostics there is certainly the determination of the structural element thickness, rebar diameters, fractures and defects detection, water content or moisture (as indicators of chemical reactions occurrence), strain. Therefore, the information obtained by the electromagnetic sensing techniques have to be converted in order to provide information directly usable by the engineers.

Not all electromagnetic sensing techniques are suitable in becoming NDT techniques. Sensing technique selection have to keep into account a certain degree of electromagnetic noise immunity, high spatial resolution and a suitable sensor size. Other aspects to be kept into account are:

- proper survey design;

- useful spatial resolution and investigation depth;

- suitable electrical contact, electromagnetic and/or mechanical coupling, precise positioning, boundary problems minimization;

- $\quad$ efficient data processing, including image processing and inversion techniques;

- $\quad$ easy data interpretation;

- possibility of data integration.

Ground Penetrating Radar (GPR) and Electrical Resistivity Tomography (ERT) have these qualities since they are active techniques providing the control on the injected signal, an adjustable spatial resolution and an useful sensor size. Moreover a number of processing codes and inversion routines are available allowing well interpretable images, although personnel with certain degree of experience is required in the data processing and interpretation.

Another class of sensors is the distributed ones, ensuring the availability of measurements along the entire envelop of the sensor. Among these, Fiber Optic Distributed Sensors based on Brillouin scattering phenomenon is a promising experimental technique able to provide field of temperature and strain along the fiber which can be a standard low cost telecommunication fiber. Unlike other fiber optic sensors, this technique permits the remote and spatially continuous monitoring of the structure in terms of temperature and strain with the resolution of some tens of centimetres.

In the following paragraphs we describe those three techniques providing examples of application and highlighting their strengths and limitations.

\subsection{Ground penetrating radar}

Ground Penetrating Radar is an electromagnetic sensing technique based on the same operating principles of classical radars (Daniels, 2004). In fact, it works by emitting an electromagnetic signal (generally modulated pulses or continuous harmonic waves) into the ground or another natural or manmade object; the electromagnetic wave propagates through the opaque medium and when it impinges on a non-homogeneity of the electromagnetic properties, in terms of dielectric permittivity and electrical conductivity, a backscattered electromagnetic field arises. Such a backscattered field is then collected by the receiving antenna located at the air/opaque medium interface and undergoes a subsequent processing and visualization, usually as a 2D image (Figure 2). 

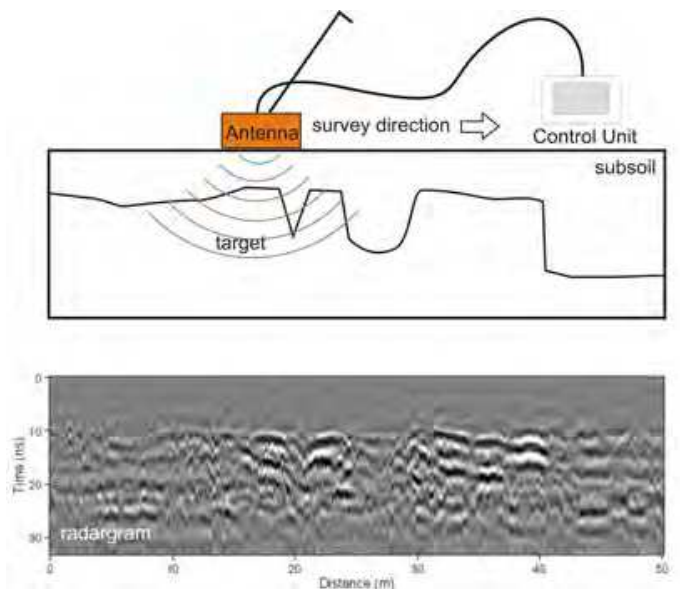

Fig. 2. GPR survey design (upper panel) and radargram (lower panel).

Spatial resolution and investigation depth of GPR method are strictly dependent by the central frequency of the used antenna. In fact, antennas with low and mid frequency $(40 \mathrm{MHz}-750 \mathrm{MHz})$ provided high investigation depth $(10 \mathrm{~m}-3 \mathrm{~m})$ associated to a relative low spatial resolution $(2 \mathrm{~m}-10 \mathrm{~cm})$. On the contrary, high central frequency antennas $(900$ $\mathrm{MHz}-2.5 \mathrm{GHz})$ provide low investigation depths $(1 \mathrm{~m}-10 \mathrm{~cm})$ and high spatial resolution $(5 \mathrm{~cm}-0.5 \mathrm{~cm})$. Since the physical size of the antennas decreases as the frequency increases, the requirement of miniaturizing the sensors is naturally achieved for the GPR.

As a consequence, the GPR technique is useful for the study of bedrock stratigraphy and cavity detection (Lazzari et al. 2006), groundwater and pollution (Chianese et al. 2006), metal and plastic pipelines such as cables in urban areas, archaeological finds (Bavusi et al. 2009) when low central frequency antennas are used.

On the contrary, when high central frequency antennas are used, the GPR, more properly named in this case Surface Penetrating Radar (SPR), can be considered a NDT technique (McCann and Forde 2001) providing precious information about the presence of "embedded" objects such as, reinforced rebars (Shaw et al., 2005; Che et al., 2009), but also embedded "defects" such as voids and, by using special antennas (Huston et al, 2000; Forest and Utsi, 2004; Utsi et al., 2008), fractures. Moreover, the GPR technique can contribute to determine the concrete moisture content (Shaari et al., 2004; Hugenschmidt and Loser, 2008;

GPR survey design is a crucial issue since it determines not only the possibility to detect the target (rebar, defect, water infiltration, ecc.), but also the format output in terms or 2D (cross section, time-slice, depth slice) or 3D data volume, kind of processing and difficult of interpretation.

A proper GPR survey design have to keep into account:

- $\quad$ orientation of searched target;

- possibility of exploit one or more suitable free surfaces;

- desired spatial resolution and investigation depth;

- mispositioning error minimization;

- format of the output;

- processing and interpretation effort minimization. 
When rebars are searched, the most used method of acquisition requires a regular orthogonal survey grid with a proper spacing (a few centimeters) in order to have a suitable spatial resolution. Figure 3 shows a the survey design performed in order to check the continuity of longitudinal and transversal rebars and check the degree of success of the concrete restoration intervention based on epoxy resin injection (Bavusi et al., 2010a).
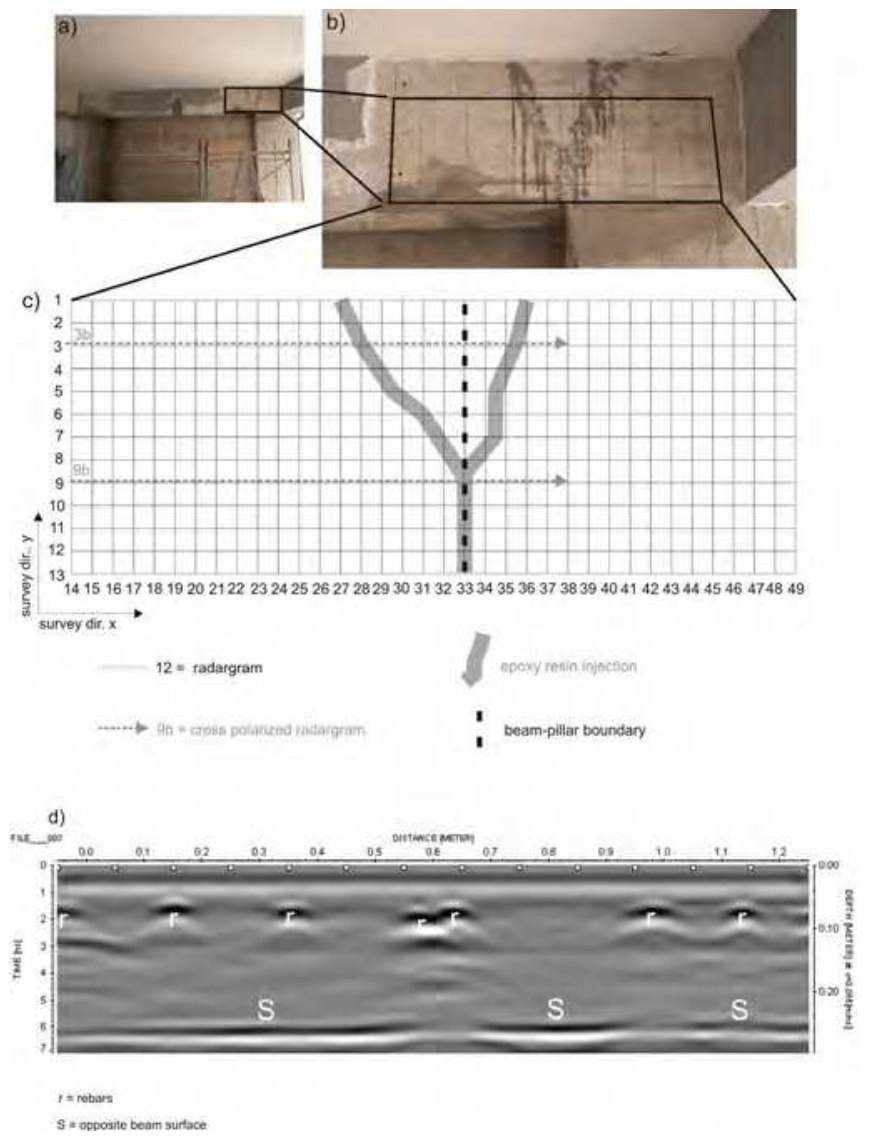

Fig. 3. GPR survey design and results on a beam of a school of L'Aquila damaged by the Abruzzo earthquake of 6th April 2009. a) beam; b) detail of damaged area with gridding; c) regular $4 \mathrm{~cm}$ square grid drawn on the beam; d) longitudinal processed radargram n.3.

A radargram has been gathered along each longitudinal and transversal survey line by using a $1500 \mathrm{MHz}$ antenna provided by survey wheel. This survey design allows to select proper cross-sections and built a data volume. In fact, transversal radargrams offer a view of longitudinal rebars, while longitudinal radargrams are useful for visualizing transversal rebars. Then, the interpolation of all radargrams allows to built a data volume and selects more significant time-slices or depth-slices in order to have a plan view of all rebars (Figure 4). 


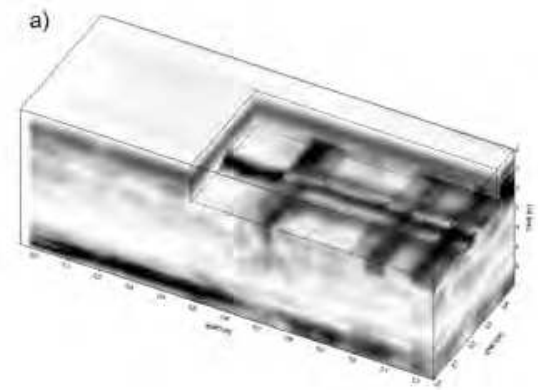

b)

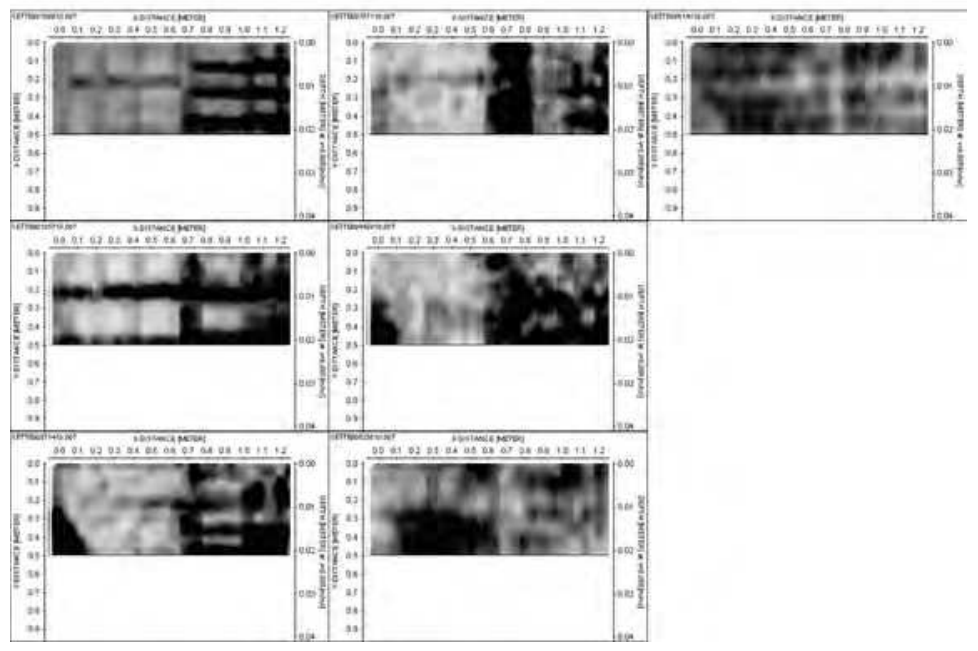

Fig. 4. a) data volume built by interpolating all radargrams gathered along the survey lines of figure 3c. b) slices extracted at several depths.

Then, GPR method provides very impressive and effective images of the inner of a reinforced concrete structure. However, the main limitation is that deeper rebar layer is not well detected due to scattering phenomena and attenuation losses producing in turn a loss in spatial definition in depth. Moreover the upper layer of rebars produces a strong disturbance on the rest of radargram.

In order to overcome this drawback, several strategies can be applied:

1. Repeating the measurements on the opposite surface of the structural element, if possible, in order to focus the other rebar layer;

2. Acquiring in cross-polarization mode: this method enables to focus the attention on the concrete matrix and not on the rebars;

3. Applying more robust inversion routines such as the Microwave Tomography.

First strategy can be effective, but increases the time consuming. The second one exploits the property of cross-polarized radargrams which are less sensitive to the rebars normal to the survey direction and more sensitive to the rebars parallel to the survey direction (Figure 5). 

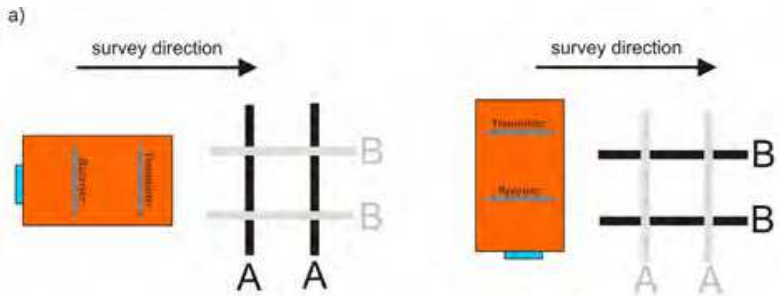

b)

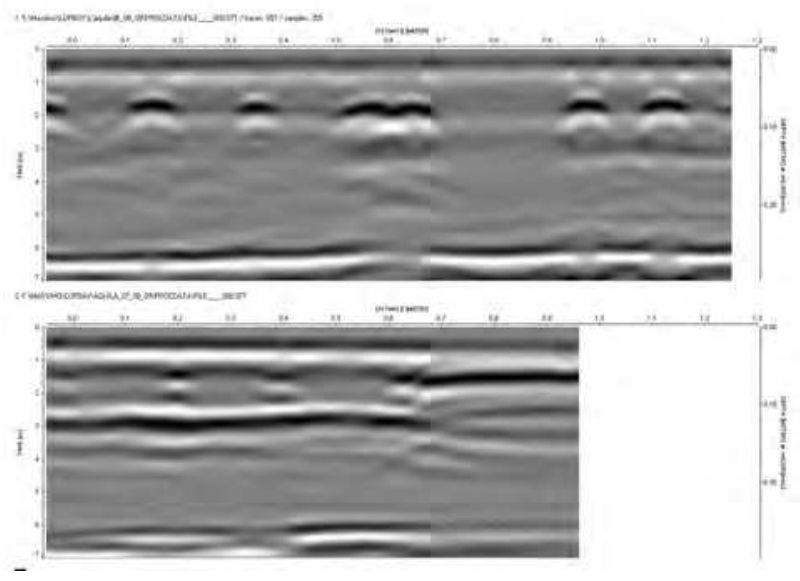

Fig. 5. a) Effect of the antenna polarization on the rebar reflection intensity. b) comparison between the normal-polarized and cross-polarized radargram gathered on the longitudinal survey lines n.9 of figure 2c.

Despite of the above mentioned advantages of GPR, one of the obstacles to its use regards the "low interpretability" of the radargram; therefore a an understandable "interpretation and visualization" of the investigated scene entails a high level operator's expertise and often a-priori information is required. This difficulty of the interpretation is further on affected in the case that no a priori information is available as, for example, it often happens in the case of historical heritage (Masini et al., 2010) where a lack of knowledge about the constructive modalities and materials of the structure can arise.

Therefore, a GPR data processing is often necessary to achieve more easily interpretable and reliable reconstructions of the scene, i.e. images that be easily understandable even by a not expert operator.

The usual radaristic approaches are based on migration procedures that essentially aim at reconstructing buried scattering objects from measurements collected above or just at the air/soil interface. These approaches were first based on graphical methods (Hagendoorn, 1954) based on high frequency assumption of the electromagnetic propagation and scattering; afterward this approach found a more consistent mathematical background based on the wave equation of the electromagnetic scattering (Stolt, 1978).

The absence of reflection in the concrete corresponding to the restored fracture indicates the success of the epoxy injection which filled all possible voids. Finally, a retrofit reinforcing intervention can be designed on the bases of the existent rebar arrangement. 
Recently, new data processing based on the inverse scattering problem have been developed and implemented also in realistic situations for infrastructure monitoring (Catapano et al., 2006; Soldovieri and Orlando, 2009, Bavusi et al., 2011). In particular, the microwave tomography approaches have arose as the most suitable ones for the on field exploitation (Soldovieri and Solimene, 2010; Persico et al., 2005).

Such a class of approaches is based on the modeling of the electromagnetic scattering phenomena. According to this modelization, the imaging problem is cast as an inverse scattering problem where one attempts to infer the electromagnetic properties of the scattering object starting from the scattered field measured somewhere outside it.

The statement of the problem is then the following: given an incident field, $E_{\text {inc }}$, which is the electromagnetic field existing in the whole space (the background medium) in absence of the scattering object and is generated by a transmitting antenna, by the interaction of the incident field with the embedded objects the scattered field $E_{S}$ arises; from the knowledge of the scattered field $E_{S}$ properties about the scattering targets, either geometrical and/or structural, have to be retrieved. The mathematical equations subtending the scattering phenomena to solve the above stated problem are in order.

To this end, we refer to a two-dimensional and scalar geometry. We consider a cylindrical dielectric object (i.e. invariant along the axis out-coming from the sheet) enclosed within the domain D illuminated by an incident field linearly polarized along the axis of invariance. The scattered field is observed over the domain $\Sigma$ (not necessarily rectilinear). Moreover, we denote by $\varepsilon(\underline{\mathrm{r}})$ e by $\varepsilon_{\mathrm{b}}(\underline{\mathrm{r}})$ the permittivity profile of the unknown object and of the background medium, respectively. In particular, the latter is not necessarily constant (i.e., a non-homogeneous background medium is allowed too) but has to be known. The magnetic permeability is assumed equal to that of the free space $\mu_{0}$ everywhere. The geometry of the problem is detailed in Figure 6.

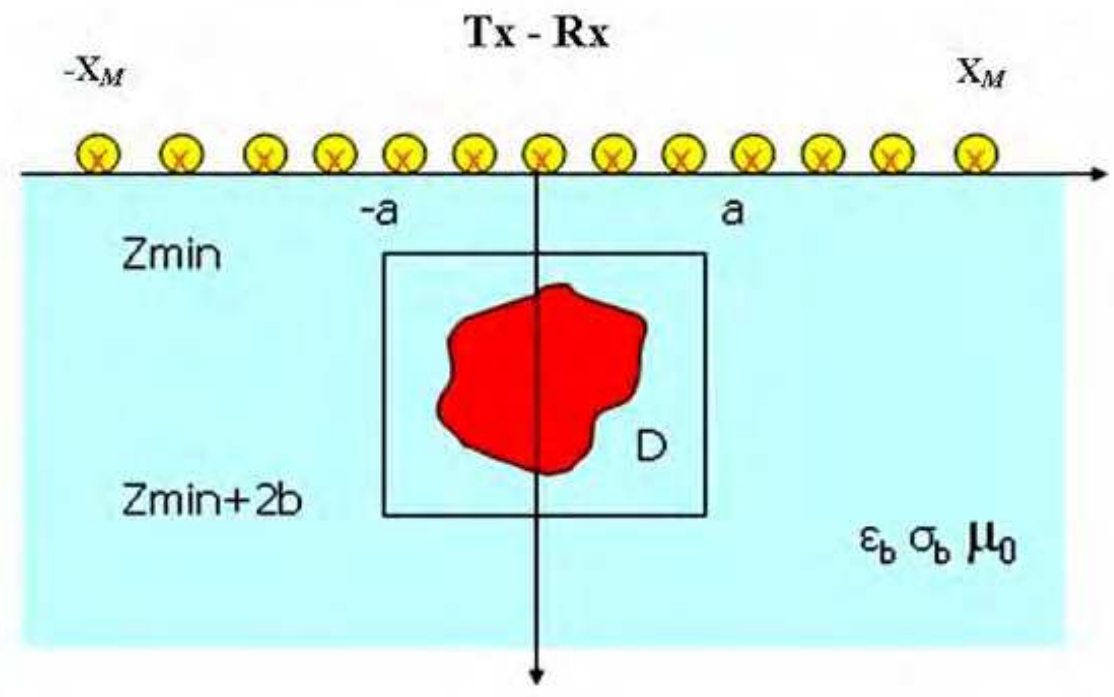

Fig. 6. Geometry of the subsurface prospecting problem 
The problem, thus, amounts to retrieving the dielectric permittivity profile $\varepsilon(\underline{\mathrm{r}})$ of the unknown object(s) from the knowledge of the scattered field $\mathrm{E}_{\mathrm{S}}$. The physical phenomenon is governed by the two equations (Chew, 1995)

$$
\begin{array}{ll}
\mathrm{E}\left(\underline{\mathrm{r}}^{\prime} \underline{\mathrm{r}}_{\mathrm{S}} ; \mathrm{k}_{\mathrm{b}}\right)=\mathrm{E}_{\mathrm{inc}}\left(\underline{\mathrm{r}}^{\mathrm{r}} \underline{\mathrm{r}}_{\mathrm{S}} ; \mathrm{k}_{\mathrm{b}}\right)+\mathrm{k}_{\mathrm{b}}^{2} \int_{\mathrm{D}} \mathrm{G}\left(\underline{\mathrm{r}}^{\mathrm{r}} \underline{\mathrm{r}}^{\prime} ; \mathrm{k}_{\mathrm{b}}\right) \mathrm{E}\left(\underline{\mathrm{r}}^{\prime}, \underline{\mathrm{r}}_{\mathrm{S}} ; \mathrm{k}_{\mathrm{b}}\right) \chi\left(\underline{\mathrm{r}}^{\prime}\right) \mathrm{d} \underline{\mathrm{r}}^{\prime} & \underline{\mathrm{r}} \in \mathrm{D} \\
\mathrm{E}_{\mathrm{S}}\left(\underline{\mathrm{r}}_{\mathrm{O}}, \underline{\mathrm{r}}_{\mathrm{S}} ; \mathrm{k}_{\mathrm{b}}\right)=\mathrm{k}_{\mathrm{b}}^{2} \int_{\mathrm{D}} \mathrm{G}\left(\underline{\mathrm{r}}_{\mathrm{O}}, \underline{\mathrm{r}} ; \mathrm{k}_{\mathrm{b}}\right) \mathrm{E}\left(\underline{\mathrm{r}}, \underline{\mathrm{r}}_{\mathrm{S}} ; \mathrm{k}_{\mathrm{b}}\right) \chi(\underline{\mathrm{r}}) \mathrm{dr} \underline{\mathrm{r}} & \underline{\mathrm{r}}_{\mathrm{O}} \in \Sigma
\end{array}
$$

where $\mathrm{E}=\mathrm{E}_{\mathrm{inc}}+\mathrm{E}_{\mathrm{S}}$ is the total field, $\mathrm{k}_{\mathrm{b}}$ is the subsurface (background) wave-number and $\chi(\underline{\mathrm{r}})=\varepsilon(\underline{\mathrm{r}}) / \varepsilon_{\mathrm{b}}-1$ is the dimensionless contrast function. $\mathrm{G}(\bullet, \bullet)$ is the pertinent Green's function (Leone and Soldovieri, 2003), $\underline{r}_{\mathrm{O}}$ is the observation point and $\underline{r}_{S}$ is the position of the source.

In accordance to the volumetric equivalence theorem (Harrington, 1961), the above integral formulation permits to interpret the scattered field as being radiated by secondary sources (the "polarization currents") which are just located within the space occupied by the targets. The reconstruction problem thus consists of inverting the "system of equations (1)" versus the contrast function. However, since (from the first of the equations 1) the field inside the buried targets depends on the unknown contrast function, the relationship between the contrast function and the scattered field is nonlinear. However, the problem can be cast as a linear one if the first line equation is arrested at the first term of its Neumann expansion. After doing this $\mathrm{E} \cong \mathrm{E}_{\mathrm{inc}}$ is assumed within the targets and the so-called Born linear model is obtained (Chew, 1995). Accordingly, the scattering model becomes

$$
\mathrm{E}_{\mathrm{S}}\left(\underline{\mathrm{r}}_{\mathrm{O}}, \underline{\mathrm{r}}_{\mathrm{S}} ; \mathrm{k}_{\mathrm{b}}\right)=\mathrm{k}_{\mathrm{b}}^{2} \int_{\mathrm{D}} \mathrm{G}\left(\underline{\mathrm{r}}_{\mathrm{O}}, \underline{\mathrm{r}} ; \mathrm{k}_{\mathrm{b}}\right) \mathrm{E}_{\mathrm{inc}}\left(\underline{\mathrm{r}}^{\prime} \underline{\mathrm{r}}_{\mathrm{S}} ; \mathrm{k}_{\mathrm{b}}\right) \chi(\underline{\mathrm{r}}) \mathrm{d} \underline{\mathrm{r}} \quad \underline{\mathrm{r}}_{\mathrm{O}} \in \Sigma
$$

Let us just remark that, within the linear approximation, the internal field does not depend on the dielectric profile, which is the same as to say that mutual interactions between different parts of any object or between different objects are neglected. In other words, this means to consider each part of the object as an elementary scatterer that does not depend on the presence of the other scatterers.

Consequently, at this point the problem can be cast as the inversion of the linear integral equation (2) and the numerical implementation of the solution algorithm requires the discretization of eq. (2). This task is pursued by resorting to the method of moments (MoM) (Harrington, 1961).

One of the main feature of a GPR data is its ability to provide images of the inner structure of a building or infrastructure at all useful observation scales by exploiting antennas with several central frequencies. Concerning this, the bridge inspection, which is normally carried out by using classical DT and NDT methods, can derive benefit from the GPR technique (Scott et al., 2003; Hugenschmidt and Mastrangelo, 2006). Structural particulars of interest are inner rebars, tendons, boundary conditions, anchors, saddles and other internal elements. On the other hand, the observation can involve the entire deck of a bridge. Such observations became crucial when all original project documentations are partially or completely lost.

Figure 7 shows the survey design drown for the deck survey of the deck of Musmeci bridge in Potenza (Basilicata Region, Southern Italy) (Bavusi et al., 2011). 

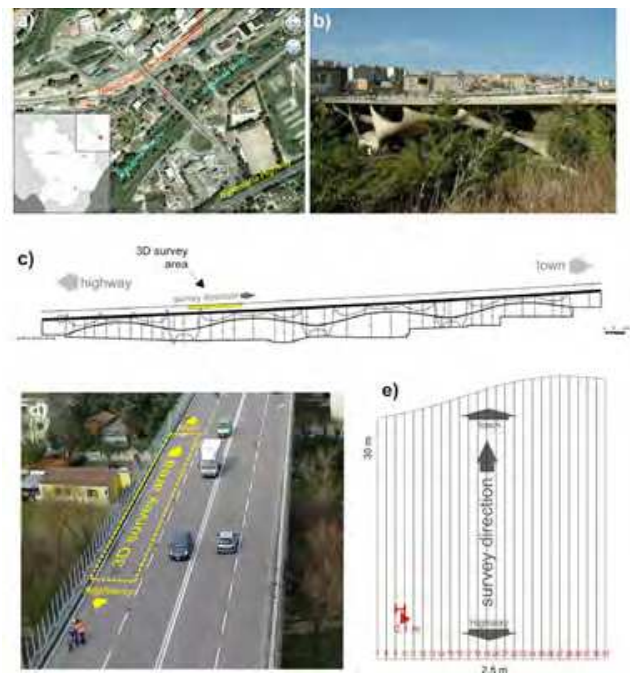

Fig. 7. a) location of the Musmeci bridge in Potenza, Basilicata Region, Italy. b) location of the survey area respect to the bridge; d) surveyed lane; e) survey grid. From Bavusi M., Soldovieri F, Di Napoli R., Loperte A., Di Cesare A., Ponzo F.C. and Lapenna V (2010).Ground Penetrating Radar and Microwave Tomography 3D applications for the deck evaluation of the Musmeci bridge (Potenza, Italy). J. Geophys. Eng. 8 (2011) 1-14. Courtesy of IOP Publishing Ltd.

A such survey design is able to provide several depth-slices in order to observe the asphalt layer, the sects layer and the lower reinforced concrete plate of the deck. Figure 8 shows more significant depth-slices showing the deck structure at several depths.
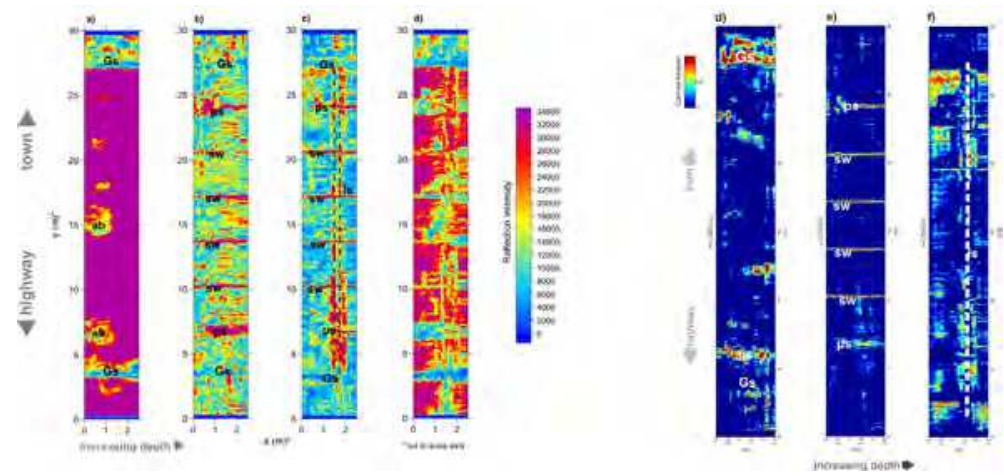

Fig. 8. a-d) depth-slices built at $6 \mathrm{~cm}$ (a), $20 \mathrm{~cm}$ (b), $40 \mathrm{~cm}$ (c) and $50 \mathrm{~cm}$ (d) by interpolating all radargrams gathered on the survey lines of figure 5e; d-f) depth-slices built at $6 \mathrm{~cm}(\mathrm{~d}), 20$ $\mathrm{cm}(\mathrm{e})$ and $40 \mathrm{~cm}(\mathrm{f})$, by interpolating the same radargrams inverted by means of the Microwave Tomography. ab: absorption zone, Gs: Gerber saddle, ps: pillar support, sw: stiffening wall, ls: longitudinal stiffening wall. From Bavusi M., Soldovieri F, Di Napoli R., Loperte A., Di Cesare A., Ponzo F.C. and Lapenna V (2010).Ground Penetrating Radar and Microwave Tomography 3D applications for the deck evaluation of the Musmeci bridge (Potenza, Italy). J. Geophys. Eng. 8 (2011) 1-14. Courtesy of IOP Publishing Ltd. 
In particular the asphalt layer shows concentrated absorptive zones that can be related to water infiltration zones. In this case the precise positioning of traces is a critical issue since it can produce a staggering effect when rectilinear features are detected. The use of a survey wheel is mandatory such as a certain degree of care in the cart dragging in order to limit mispositioning errors. In this way a residual error can be subsequently reduced by using proper algorithms.

Among possible defects afflicting buildings and infrastructures, fractures are a very warring problem. In fact, fractures can be due to several causes: temperature $(3 \mathrm{~mm})$, dry up $(0.4 \mathrm{~mm})$, load $(0.4 \mathrm{~mm})$. They can involve loss of mechanical strength and represent a preferential way for the water infiltration which in turn can favour the developin $g$ of chemical reactions (expanding salt crystallization, oxidation, carbonation, etc.).

Crack detection is an important issue in the field of non-destructive testing. Several techniques can be employed in order to check, localize and characterize fractures in manmade buildings: ultrasonic shear waves (De La Haza et al. 2008), elastic waves (Ohtsu et al. 2008), GPR (Utsi et al. 2008).

Due to their small size and variable orientation, fractures detection represents a very challenge for the GPR technique. In fact, the crack detection requires the exploitation of all spatial resolution available in the frequency range used. Moreover it requires fracture to be surveyed is filled by air, water or a material different from the host medium in order to produce a backscattered field (Grandjean and Gourry 1996). In addition, the geometry of the fracture with respect to the survey line plays a fundamental role (Tsoflias et al. 2004). For a vertically oriented fracture, a reflection hyperbola arises due to the bottom of the fracture and to each change in the direction of the fracture with respect to the vertical path (Forest and Utsi 2004). By exploiting this property, it is theoretically possible to detect a fracture by using a common GPR dipole antenna, even the use of specifically designed high vertical resolution antennas is very helpful (Forest and Utsi 2004; Utsi et al. 2008). Moreover, data processing plays a fundamental role to improve the 'imaging' and the focusing of the buried reflectors (Grandjean and Gourry 1996; Leucci et al. 2007).

Figure 9 shows a $1500 \mathrm{MHz}$ GPR survey carried out on a fracture in the floor of the Prefecture of Chania (Crete Island, Greece) (Bavusi et al., 2010b).

Fracture zone, located at the middle point of the radargram, is detected by using a classical processing approach, but best performances in terms of spatial resolution can be obtained by using the Microwave Tomography.

\subsection{Electrical resistivity tomography}

Electrical resistivity tomography (ERT) is an electromagnetic sensing technique used to obtain 2D and 3D images in terms of electrical resistivity of areas of complex geology (Griffiths and Baker 1993), landslides, watertable, basins, faults.

Technically, during an electrical resistivity measurement, the electric current is injected into the ground via two $30-40 \mathrm{~cm} \times 1.5 \mathrm{~cm}$ steel electrodes and the resulting electrical voltage is measured between two other electrodes in line with current electrodes (Sharma, 1997). ERT can be carried out by using different electrode configurations such as dipole-dipole, Wenner, Schulumberger, pole-dipole, etc. (Figure 10).

At present, such configurations can be carried out by using multi-electrode systems enabling the automatic switch of all available electrodes previously fixed into the ground. The system manages the current injection and simultaneous potential measurements which can occur simultaneously at more potential electrodes in case of multichannel systems. 

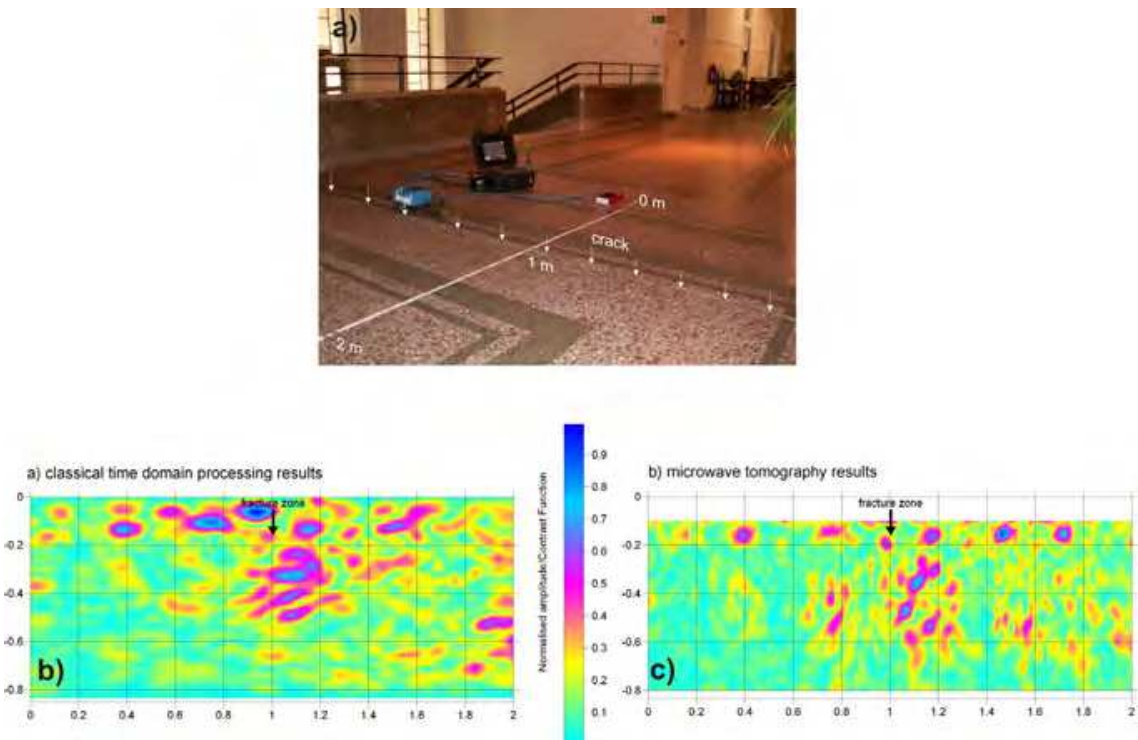

Fig. 9. a) GPR survey design carried out at the Prefecture of Chania (Crete, Greece) on a fracture in the floor. Fracture zone is at the middle point of the radargrams. b) processed radargram; $c$ ) Microwave Tomography From Bavusi M., Soldovieri F., Piscitelli S., Loperte A., Vallianatos F. and Soupios P. (2010). Ground-penetrating radar and microwave tomography to evaluate the crack and joint geometry in historical buildings: some examples from Chania, Crete, Greece. Near Surface Geophysics, Vol.8, No. 5, pp. 377-387. Courtesy of EAGE Publications BV..

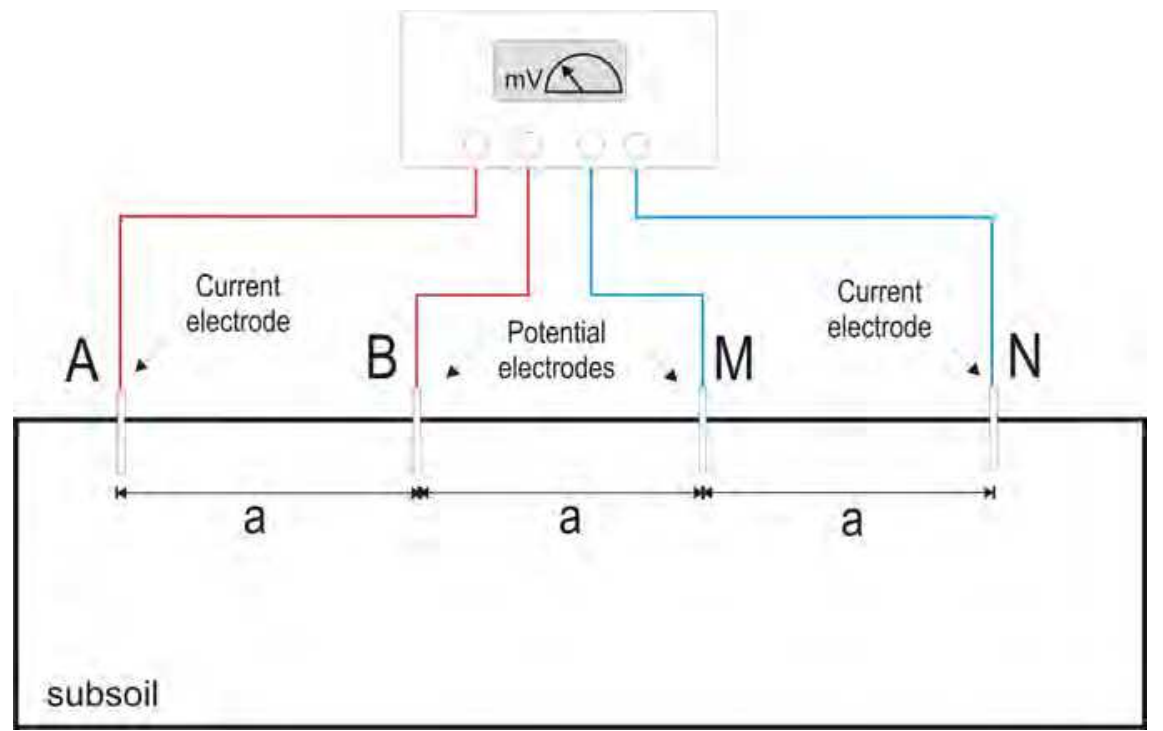

Fig. 10. a) Dipole-dipole array for the acquisition of a measure of electrical resistivity. 
The result of an ERT survey is a distribution 2D or 3D of apparent resistivity where each data point is defined by two coordinates ( $x$ and $z$ ) depending on the position of the quadrupole (couple of current and potential dipoles) used and a value of apparent resistivity. Then, in order to reconstruct real resistivity distribution, an inversion routine is required. A number of algorithms are available in order to perform this reconstruction such as Res2DInv (Loke and Barker, 1996) for the automatic 2D inversion of apparent resistivity data was used. The inversion routine is based on the smoothness constrained least-squares inversion (Sasaki, 1992) implemented by a quasi-Newton optimization technique.

ERT surveys have been successfully applied in geology for stratigraphy and cavity detection (Lazzari et al., 2010), fault characterization (Caputo et al., 2007), landslide studies (Lapenna et al., 2005), in hydrogeology, in environmental problems for contaminant plume detection and waste dump characterization (Bavusi et al., 2006), for hydrogeology and coastal salt water intrusion detection (Satriani et al., 2011a), in agricultural for the root-zone characterization (Al Hagrey, 2007; Satriani et al, 2011b), in archaeology and cultural heritage studies (Bavusi et al., 2009). Figure 11 shows an example of ERT carried out on a piling in an area subjected to landslides. It is well visible the effect of the structure on the water distribution.

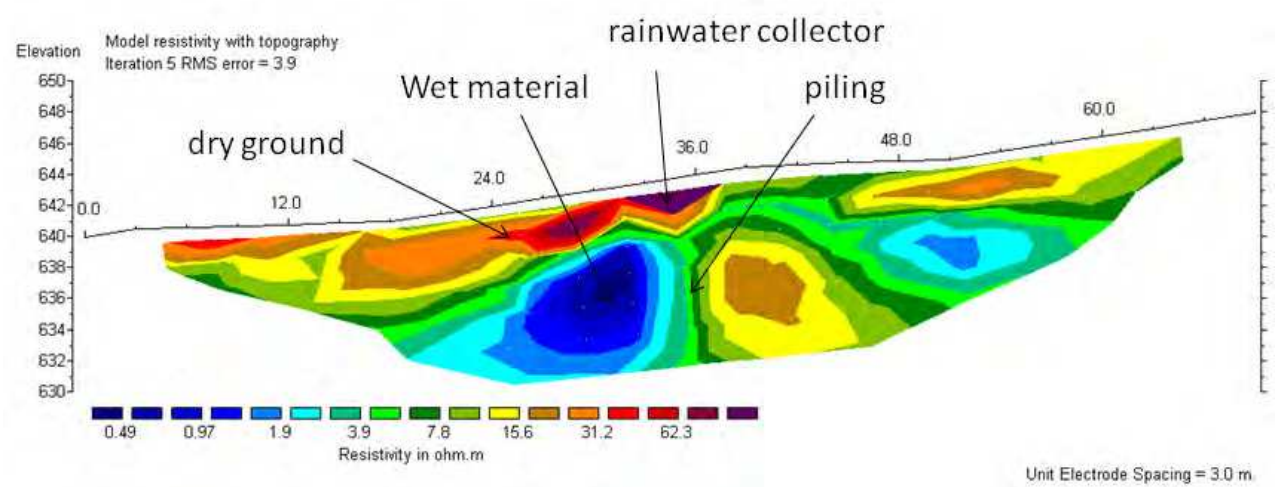

Fig. 11. Example of ERT carried out on a piling in an area subjected to landslides.

The ERT exhibits significant potentialities in terms of high resolution and flexibility of the investigation depth that can be varied in a simple way, by varying the electrode spacing. A large electrode spacing provides a high investigation dept and a low spatial resolution. On the contrary, a small electrode spacing allows to achieve a great spatial resolution but a low investigation depth.

This characteristic makes the ERT a candidate for the structure and infrastructure monitoring, even though some problems have to be enfaced. First, a structure or infrastructure survey requires an electrode spacing ranging between one centimeter and some decimeter, then sensors have to miniaturized in order to respect the assumption of geophysics stating transducers have to be punctual (i.e. small respect to dimension of the investigated volume) and reduce modeling errors (Cosentino et al. 2011; Athanasiou et al., 2007). Then, a low contact resistance have to be ensured in order to put an adequate current injection (Cosentino et al. 2011). 
In order to meet these requirements, several devices can be used such as $\mathrm{Cu}$ flat-base electrodes with conductive gel (Athanasiou et al., 2007), $\mathrm{Ag} / \mathrm{AgCl}$ medical electrodes and nails (Cosentino et al 2011), Cu-CuSO electrodes (Seppänen et al., 2009). Main limitation of these devices is the difficulty of put them on a vertical or steeply slope surface, even worse under a ceiling. Moreover, medical electrodes are not stable in time (Cosentino et al 2011), while flat-base electrodes are not suitable for the asphalt, where the only possibility to apply the ERT is making holes in order to put the electrode in the substratum.

In spite of these limitations, the ERT has been successfully applied on masonry, floors, artifacts in order to detect fractures, voids, previous restoration works, structural particulars, moisture. The application to reinforced concrete is possible in order to detect those targets and rebars, but experiments demonstrates target detection capacity in simple geometrical configurations (Seppänen et al., 2009; Karhunen et al., 2009).

In presence of complex rebar configurations such as reinforcement cages, the potential field produced by the injected current suffers a warping due to the circuit represented by the cage not easily modelable. A new class of inversion routines is then required in order to solve this problem. This technique appears still not adequate to be applied to structures and infrastructures, but technological development can provide technical solutions able to mitigate and overcame described limitations.

\subsection{Distributed fiber optic sensors}

Typically standard NDT systems are based on the use of point sensors, however the Structural Health Monitoring (SHM) of large civil infrastructures like bridges, dams could require a large number of sensors. For these applications, there is an increasing interest towards the use of distributed optical fiber sensors. In these sensors is the optical fiber itself that acts as a sensor providing measurements all along the fiber. This approach permits to monitoring the whole structure by use of a single optical fiber avoiding the need of a huge amount of measurement points and lead to the comprehension of the real static behavior of the structure rather than a limited number of sensors. Furthermore, distributed sensors could play a fundamental role in civil engineering because no other tools allow the detection of local phenomena whose location is impossible to be predicted "a priori" like, for instance, for crack detection. Distributed fiber optic sensors are substantially different from other fiber optic sensors technologies being based on optical scattering mechanism (Raleigh, Raman, Brillouin) occurring during light propagation in common telecom optical fibres.

Spatial resolution is typically achieved by using the optical time domain reflectometry (OTDR) (Barnoski 1976), in which optical pulses are launched into an optical fiber and consequent variations in backscattering intensity is detected as a function of time. Alternative detection techniques such as frequency-domain approaches have been also demonstrated. Raleigh scattering based sensors were first developed, in order to locate fiber breaks or bad splices along a fiber link. However Rayleigh backscatter in standard fibers gives information only about optical attenuation, and it can not be related to other parameters such as temperature or strain. Distributed temperature sensing was first demonstrated by Hartog and Payne (1982), who used temperature-induced variation of the Rayleigh scattering coefficient along the length of liquid-core, but the low reliability of liquid-core fibers may restrict their use. A recent, very interesting approach makes use of the very high spatial resolution allowed by sweptwavelength interferometry, in order to correlate temperature and strain of the fiber with the spectrum of the Rayleigh backscatter spatial fluctuations (Measures 2001). This approach 
requires standard telecommunication fibers and very high spatial resolution (a few millimeters) has been demonstrated. On the other hand, the main disadvantages are the equipment cost (a tunable laser source is needed for the measurements), and the limited sensing length $(70 \mathrm{~m})$. Dakin et al. (1985) demonstrated temperature profiles measurement using the variations in the Raman backscattering coefficients of anti-Stokes and Stokes light. The Raman approaches are very practical because conventional silica-based optical fibers can be used as the sensor. The anti-Stokes-Raman-backscattered light is about $30 \mathrm{~dB}$ weaker than the Rayleigh-backscattered light. However, its sensitivity to temperature is great. Therefore, systems based on Raman scattering have been commercialized by several manufacturers. Nevertheless, Raman scattering based systems do not allow performing deformation measurements. In 1989, it was reported that the frequency shift of the Stokes-Brillouinbackscattered light (the so-called Brillouin frequency shift) greatly varies with strain and temperature along the fiber (Horiguchi 1989, Culverhouse 1989). Since then, considerable attention has been paid to exploiting Brillouin scattering for distributed sensing. This is for the following reasons. First, strain is a very important parameter in the monitoring of the integrity of civil structures. Secondly, unlike the Raman technique, Brillouin frequency shift measurement does not require calibration of the optical-fiber loss. Furthermore, a very attractive feature of Brillouin-based sensors stems from the use of a standard telecommunications-grade optical fiber as the sensor head. The low-cost and low-loss nature of the sensor make possible to perform distributed measurements over distances of many kilometers. Finally, the tremendous developments in the optical telecommunications market have reduced considerably the cost and increased the performances of optical fibers and their associated optical components.

Distributed optical fiber sensors based on stimulated Brillouin scattering (SBS) rely on the interaction between two lightwaves and an acoustic wave in the optical fiber. The measurement principle is based on the characteristic that the Brillouin frequency of the optical fiber is shifted when strain as well as temperature changes occur. Spatial information along the length of the fiber can be obtained through Brillouin optical time domain analysis (BOTDA) by measuring propagation times for light pulses travelling in the fiber. This allows for continuous distributions of the parameter to be monitored.

The research in the beginning of distributed fiber optic strain sensing was mostly based on laboratory applications (Bernini 2005, Bernini 2008) only in last years in-field demonstration by a fully distributed sensor have been previously reported (Komatsu 2002).

About bridge structures recently the applications and the validation of distributed strain sensor during load test has been demonstrated (Matta 2008, Minardo 2011). Other examples are the installation of a distributed fiber optic strain sensing cable into the inspection gallery of a dam (Inaudi and Glisic 2005, Glisic and Inaudi, 2007) or the monitoring of extra-long tunnel, running over $150 \mathrm{~km}$ of seafloor geologic body with complicated topographic and geologic units (Shi, 2003).

However, the use of distributed fiber optic sensors for crack detection in concrete are rare. This is mainly due to the fact that the instrumentations available for in-field application have a limited spatial resolution (1m) (Deif 2010). In fact, distributed sensors measure the with average strain at each measurement point, where the strain is averaged over the length called spatial resolution. Today, new methods for distributed fiber optic strain sensing with sub-meter spatial resolution are being developed in order to increase the opportunities in NDT of civil structures especially for crack detection (Hotate 2002, Zou 2005, Bernini 2007). 
As an example, we report the results obtained in a load test on a road-bridge (Minardo 2011). In particular, the tests were performed by an stimulate Brilouin Scattering portable sensor prototype with $3 \mathrm{~m}$-spatial resolution. The fiber employed for the measurements was a PVC-coated, single-mode, standard telecom optical fiber. The fiber was bonded along the lower flange of a 44-m-long, double-T steel beam, by use of a epoxy adhesive. Strain measurements were performed while loading the bridge with an increasing weight by use of gravel-loaded trucks (Figure 12a). During the loading test, data were also collected by other instruments for a cross-correlation. In particular, two vibrating wire (VW) strain gauges were previously spot-welded to the surface of the steel beam, so as to provide the strain at the quarter and the middle section of the loaded beam. Figure 10b depicts the results of the optical fiber measurements, for different load conditions. In particular, the solid lines refer to the bridge loaded by two, four, and five gravel trucks, respectively. Each truck had a weight of approximately 47 tons. The same figure also reports the results of a finite-element-method (FEM)-based numerical analysis (circles). Numerical data were obtained by modelling each gravel truck as three concentrated loads applied in correspondence of the three truck axles. A good agreement exists between the experimental and numerical data. The standard deviation was always less than $20 \mu \varepsilon$, corresponding to the nominal accuracy of the instrument. Moreover, the maximum strain provided by the optical fiber sensor $(\approx 350 \mu \varepsilon)$, is in good agreement with the value provided by the strain gauge placed at the middle beam section $(\approx 330 \mu \varepsilon)$. Another interesting feature is that the optical fiber sensor was able to reveal the right-shift of the center of gravity (CG), when loading the beam with five trucks. Actually, the fifth truck was not disposed symmetrically with respect to the middle of the bridge; rather it was closer to the right side. As a consequence, the section at which maximum strain occurs is shifted to the right in the final load test. Finally, in figure $12 \mathrm{~b}$ are also reported, for comparison, the data obtained by the strain gauges (squares). As can be observed a good agreement between the two different observations is achieved.
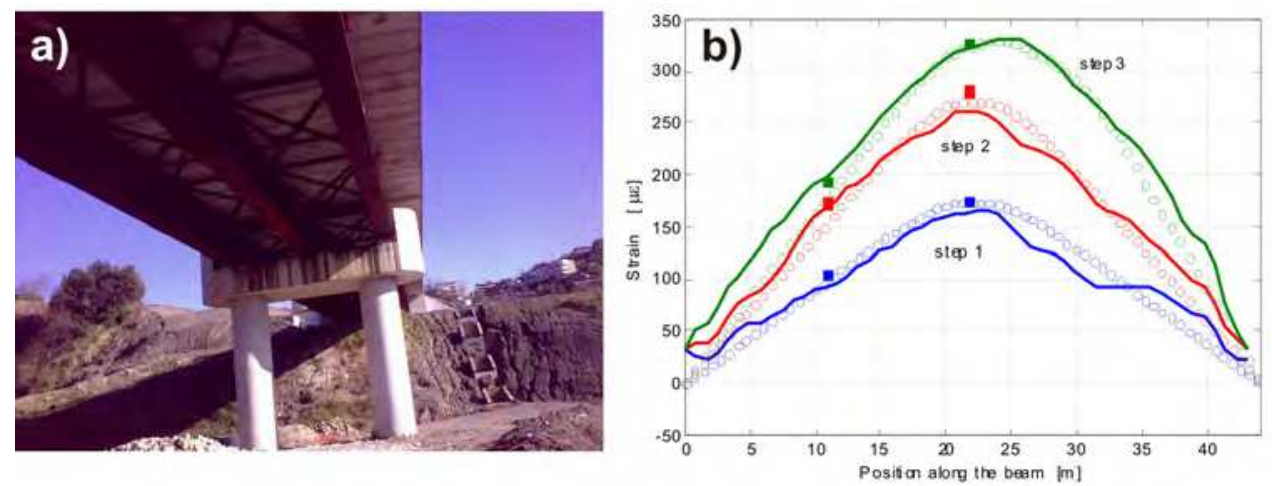

Fig. 12. a) bridge used for the load test. b) Distributed strain measurement along the girder, for different load conditions (solid lines). FEM simulations (open circles). VW strain gauges (squares). 


\section{Conclusion}

Health monitoring of civil engineering structures is devoted to assess the structural integrity and dynamic behaviour during a seismic event in order to define appropriate activities for risk mitigation. This need is more stringent for aged infrastructures built following outdated codes of practice and where the chemical degradation of concrete and irons acted for more time.

The design of suitable retrofit strategies requires a series of test assessments in order to define the vulnerability. A number of destructive (DT) and non destructive tests (NTD) and methods has been developed and applied around the world in order to achieve all necessary information about construction material. An appropriate survey have to include a suitable proportion of DT and NDT methods in order to reduce possible damage to investigated structure, achieve a balanced combination of punctual and distributed information and reduce the global cost of the survey.

Then, the requirement of new non invasive technique is a stringent need that can be satisfied by the electromagnetic sensing techniques, this class of geophysical techniques which can be easily adapted to the specific requirements of civil infrastructures. This is the case of the Ground Penetrating Radar which at high frequencies provides the needed spatial resolution and a convenient small size of the antenna. Moreover, this technique can benefit on a new kind of processing based on the Microwave Tomography (MT) inversion. In this way the technique can focus small defects such as fractures and voids, detect rebars with great precision even if deep. The combination of GPR and MT will provide in future a new class of devices able to supply a not focused image ready for use by non expert users.

The Electrical Resistivity Tomography can be another suitable technique useful to depict embedded structural particulars and defects, but its systematic application requires to solve two problems. First is the design of appropriate non intrusive electrodes, stable in time and easy to install in any position. A solution can be provided by medical industries that have experience in the design of electrodes for human body applications. The latter is the lack of inversion routines able to model the effect of a rebar cage on the potential field and properly reconstruct the inner of a reinforced concrete structure. Anyway the ERT is successfully applied on floors, pavements, masonry and reinforced concrete structures having a simple inner arrangement. Moreover, the industry will provide in future new sensors, equipments and inversion routines able to mitigate or solve described problems.

Another class of sensors which will change the way of monitor a civil infrastructure is the distributed fiber optic sensor able to provide temperature and strain information along the fiber. This sensor is based on standard telecom fiber optic which is inexpensive and allows to design sensor sized on the infrastructure to be surveyed or on a particular. It allows to achieve in real time information by several points of a distributed civil infrastructure such as a railway, aqueduct, gas or oil pipeline without using transmission devices. In future optic fibers will be embedded in construction materials allowing a for life monitoring of an infrastructure. Moreover, a possible technological improvement of this technique can allow in future its application to the ambient vibration monitoring (Wenzel and Pichler, 2005). 


\section{Acknowledgment}

The research leading to these results concerning the Musmeci bridge has received funding from the European Community's Seventh Framework Programme (FP7/2007-2013) under Grant Agreement n² 225663 Joint Call FP7-ICT-SEC-2007-1.

Moreover, the authors would like to thank the "Soprintendenza per i Beni Architettonici e Paesaggistici della Basilicata" and the "Direzione Regionale per i beni Culturali e Paesaggistici della Basilicata" that have partially funded the activities. Finally, the authors would like to thank the owner of the Musmeci Bridge, ASI Consortium, for their interest to these research activities and the Municipality of Potenza for the granted authorization to access and work on the structure. Furthermore, the authors would like to thank EAGE Publications BV and IOP Publishing Ltd for copyright permissions granted.

Finally, the authors would like to thank TeRN Consortium for supporting this work.

\section{References}

A.C.I. 214.4R (2003). Guide for Obtaining Cores and Interpreting Compressive Strength Results.

Al Hagrey, S.A., (2007). Geophysical imaging of root-zone, trunk, and moisture heterogeneity, J. Exp. Bot., Vol. 58, pp. 839-854.

Ansari F.(2005). Sensing issues in civil structural health monitoring. Spinger.

Athanasiou E.N. , Tsourlos P.I., Vargemezis G.N., Papazachos C.B. and

Barlet, F.M. \& MacGregor, J. (1994). Effect of Core Diameter on Concrete Core Strengths. ACI Materials Journal, Vol. 91, No. 5, September-October.

Barnoski J. K., Jensen S. M., (1976). Fiber waveguides: A novel technique for investigation attenuation characteristics. Appl. Opt., Vol. 15, pp. 2112 - 2115.

Bavusi M., Rizzo E., Lapenna V. (2006). Electromagnetic methods to characterize the Savoia di Lucania waste dump (Southern Italy). Environmental Geology, Vol. 51, No. 2, pp. 301-308. DOI 10.1007/s00254-006-0327-9

Bavusi M., Rizzo E., Giocoli A., Lapenna V., (2009). Geophysical characterisation of Carlo's V Castle (Crotone, Italy). Journal of Applied Geophysics, Vol. 67, No. 4, ,pp. 386-401.

Bavusi, M., Loperte, A.; Lapenna, V., Soldovieri, F., (2010a). Rebars and defects detection by a GPR survey at a L'Aquila school damaged by the earthquake of April 2009., 2010 13th International Conference on Ground Penetrating Radar (GPR), 21-25 June 2010.

Bavusi M., Soldovieri F., Piscitelli S., Loperte A., Vallianatos F.and Soupios P. (2010b). Ground-penetrating radar and microwave tomography to evaluate the crack and joint geometry in historical buildings: some examples from Chania, Crete, Greece. Near Surface Geophysics, Vol.8, No. 5, pp. 377-387.

Bavusi M., Soldovieri F., Di Napoli R., Loperte A., Di Cesare A., Ponzo F. C. and Lapenna V. (2011). Ground Penetrating Radar and Microwave Tomography 3D applications for the deck evaluation of the Musmeci bridge (Potenza, Italy). Journal of Goph. and Eng, No. 8, pp. 1-14. 
Bernini R., Fraldi M., Minardo A., Minutolo V., Carannante F., Nunziante L, Zeni L. (2005). Damage detection in bending beams through Brillouin distributed optic-fibre sensor. Bridge Struct. Vol. 1, 355-363.

Bernini R., Minardo A., Zeni L., (2007). Accurate high-resolution fiber-optic distributed strain measurements for structural health monitoring. Sensors and Actuators A, Vol. 134, pp. 389-395.

Bernini R., Minardo A., Zeni L. (2008). Vectorial dislocation monitoring of pipelines by use of Brillouin-based fiber-optics sensors. Smart Mater. Struct., Vol. 17, pp. 015006,

Braga, F., Dolce, M., Masi, A., Nigro, D. (1992). Valutazione delle caratteristiche meccaniche dei calcestruzzi di bassa resistenza mediante prove non distruttive. L'Industria Italiana del Cemento, Vol. 3, pp. 201-208.

Caputo R., Salviulo L., Piscitelli S., Loperte A., (2007). Late Quaternary activity along the Scorciabuoi Fault (Southern Italy) as inferred from electrical resistivity tomographies. Annals of Geophysics, Vol. 50, No., 2, pp.213-224.

Catapano I., Crocco L., Persico R., Pieraccini M., Soldovieri F. (2006). Linear and Nonlinear Microwave Tomography Approaches for Subsurface Prospecting: Validation on Real Data. Antennas and Wireless Propagation Letters, Vol. 5, pp. 49-53.

Che W. C., Chen H. L. and Hung S. L. (2009). Measurement radius of reinforcing steel bar in concrete using digital image GPR. Constr. Build. Mater., Vol. 23, pp. 10571063.

Chew C. W.(1995). Waves and Fields in inhomogeneous media. Piscataway,NJ: IEEE Press.

Chianese D., D’Emilio M., Bavusi M., Lapenna V., Macchiato M. (2006). Magnetic and ground probing radar measurements for soil pollution mappingin the industrial area of Val Basento (Basilicata Region, Southern Italy): a case study. Environ Geol , Vol. 49, pp. 389-404.

Cosentino P.L., , Capizzi P., Martorana R., Messina P. and Schiavone S. (2011). From Geophysics to Microgeophysics for Engineering and Cultural Heritage. International journal of Geophysics, Vol. 2011, pp. 1-8. DOI: $10.1155 / 2011 / 428412$.

Culverhouse D., Fahari F., Pannell C. N., Jackson D. A.(1989). Potential of stimulated Brillouin scattering as sensing mechanism for distributed temperature sensors. Electron. Lett., Vol. 25, No. 14, pp. 913-915.

Dakin J. P., Pratt D.J, Bibby G. W., Ross J. N., (1985), Distributed optical fiber Raman temperature sensor using a semiconductor light source and detector, Electron. Lett., Vol. 21, No. 13, pp. 569-570.

Daniels D.J. (2006). Ground Penetrating Radar. 2nd edition. Institution of Engineering and Technology, pp.634. DOI: 978-0-86341-360-5; electronic DOI: 978-1-59124-893-4

De La Haza A.O., Petersen C. G. and Samokrutov A. (2008). Three dimesional imaging of concrete structures using ultrasonic shear waves. Structural Faults E Repair-2008, 12th International Conference, Edinburgh, UK: 10th -12th June 2008.

Deif A., Martın-Perez B., Cousin B., Zhang C., Bao X., Li W. (2010). Detection of cracks in a reinforced concrete beam using distributed Brillouin fibre sensors. Smart Mater. Struct., Vol. 19, 055014. 
Ditommaso R., Parolai S., Mucciarelli M., Eggert S., Sobiesiak M. and Zschau J. (2010a). Monitoring the response and the back-radiated energy of a building subjected to ambient vibration and impulsive action: the Falkenhof Tower (Potsdam, Germany). Bulletin of Earthquake Engineering. Vol..8, No. 3. DOI: 10.1007/s10518009-9151-4.

Ditommaso R., Mucciarelli M., Ponzo F. C. (2010b). S-Transform based filter applied to the analysis of non-linear dynamic behaviour of soil and buildings. 14th European Conference on Earthquake Engineering. Ohrid, Republic of Macedonia, August 30 September 03.

Ditommaso R, Mucciarelli M., Ponzo F. C. (2011). Analysis of non-stationary structural systems by using a band-variable filter. Submitted to Bulletin of Earthquake Engineering.

Douglas A. (2007). Health Monitoring of Structural Materials and Components: Methods with Applications. Copyright (C) 2007 John Wiley \& Sons, Ltd.

Forest R. and Utsi V. (2004). Non destructive crack depth measurements with ground penetrating radar. 10th Int. Conf. on Ground Penetrating Radar,Delft, The Netherlands, 21-24 June 2004.

Glisic B. and Inaudi D. (2007). Fibre Optic Methods for Structural Health Monitoring. John Wiley \& Sons. ISBN: 0470061421.

Grandjean C. and Gourry J.C. (1996). GPR data processing for 3D fracture mapping in a marble quarry (Thassos, Greece). Journal of Applied Geophysics, Vol. 36, pp.19-30.

Griffiths, D.H. and R.D. Baker (1993): Two-dimensional resistivity imaging and modelling in areas of complex geology. J. Appl. Geophys., Vol. 29, pp. 211-226.

Hagedoorn, J. G. (1954). A Process of Seismic Reflection Interpretation. Geophys. Prospect. Vol. 2, pp 85-127.

Harrington, R.F. (1961). Time-Harmonic Electromagnetic Fields, Mc Graw Hill.

Hartog A. H., and D. N. Payne (1982). Remote measurement of temperature distribution using an optical fiber. Proc. ECOC '82, Cannes, France, pp. 215-220, 1982.

Horiguchi T, Kurashima T., Tateda M., (1989). Tensile strain dependence of Brillouin frequency shift in silica optical fibers. IEEE Photonics Tech. Lett., Vol. 1, No. 5, pp. 107-108.

Hotate K., Tanaka M., (2002). Distributed fiber Brillouin strain sensing with 1-cm spatial resolution by correlation-based continuous-wave technique. IEEE Phot. Technol. Let. Vol. 14, 179-181.

Hugenschmidt J. and Mastrangelo R. (2006). GPR inspection of concrete bridges Cem. Concr. Compos., Vol. 28, pp. 384-92.

Hugenschmidt J. and Loser R. (2008). Detection of chlorides and moisture in concrete structures with ground penetrating radar. Mater. Struct. Vol. 41, pp. 785-92

Huston D., Hu J. Q., Maser. K., Weedon W. and Adam C. (2000). GIMAground penetrating radar system for monitoring concrete bridge decks. J. Appl. Geophys., Vol. 43, pp. 139-46.

Inaudi D., Glisic B., (2005). Application of distributed Fiber Optic Sensory for SHM", 2nd International Conference on Structural Health Monitoring of Intelligent Infrastructure (SHMII-2'2005), Shenzhen, China, November 16-18. 
Karhunen K., Seppänen A., Lehikoinen A.\&. Kaipio J.P,(2009). Locating reinforcing bars in concrete with Electrical Resistance Tomography. Concrete Repair, Rehabilitation and Retrofitting II - Alexander et al (eds). (C) 2009 Taylor \& Francis Group, London, ISBN 978-0-415-46850-3

Komatsu, K., Fujihashi, K. \& Okutsu, M., (2002). Application of optical sensing technology to the civil engineering field with optical fiber strain measurement device (BOTDR). Proc. SPIE, Vol. 4920: 352-361.

Lapenna V., Lorenzo P., Perrone A., Piscitelli P., Rizzo E. Sdao F., (2005). 2D electrical resistivity imaging of some complex landslides in the Lucanian Apennine chain, southern Italy. Geophysics, Vol. 70, No. 3; pp. B11-B18. DOI: $10.1190 / 1.1926571$

Lazzari M., Loperte A., and Perrone A. (2006). Near surface geophysics techniques and geomorphological approach to reconstruct the hazard cave map in historical and urban areas. Adv. Geosci., Vol. 24, pp. 35-44.

Leucci G., Persico R. and Soldovieri F. (2007) Detection of fractures from GPR data: the case history of the Cathedral of Otranto. J. Geophys. Eng., Vol. 4, pp. 452-461.

Lazzari M., Loperte A., and Perrone A. (2010). Near surface geophysics techniques and geomorphological approach. Adv. Geosci., Vol. 24, pp. 35-44.

to reconstruct the hazard cave map in historical and urban areas

Leone G. and Soldovieri F. (2003). Analysis of the distorted Born approximation for subsurface reconstruction: truncation and uncertainties effect", IEEE Trans. Geoscience and Remote Sensing, vol. 41, no. 1, pp. 66-74, Jan.

Loke, M.H and Baker R.D., (1996). Rapid least-squares inversion of apparent resistivity pseudosections by quasi-Newton method. Geophys. Prospect., Vol. 44, pp.131-152.

Masini L, Persico R., Rizzo E, Calia A, Giannotta m. T., Quarta G., Pagliuca A. (2010). Integrated Techniques for Analysis and Monitoring of Historical Monuments: the case of S.Giovanni al Sepolcro in Brindisi (Southern Italy). Accepted for publication on Near Surface Geophysics.

McCann D. M., Forde M. C. (2001). Review of NDT methods in the assessment of concrete and masonry structures. NDTEE International, Vol. 34, pp. 71-84

Matta F., Bastianini F., Galati N., Casadei P., Nanni A. (2008). Distributed Strain Measurement in Steel Bridge with Fiber Optic Sensors: Validation through Diagnostic Load Test. ASCE Journal of Performance of Constructed Facilities, Vol. 22, pp. 264-273.

Measures R. M., Structural monitoring with fiber optic technology. Academic Press, 2001

Minardo A., Bernini R., Amato L., Zeni L., (2011). Bridge monitoring using Brillouin fiberoptic sensors. IEEE Sensors Journal, Vol. 99, pp.

Moustafa A., Mahadevan S., Daigle M., Biswas G. (2010). Structural and sensor damage identification using the bond graph approach. Structural Control and Health Monitoring, 17: 178-197.

Ohtsu M., Tokay M., Ohno K. and Isoda T., (2008). Elastic-wave methods for crack detection and damage evaluation in concrete. Structural Faults \& Repair-2008, 12th International Conference, Edinburgh, UK: 10th -12th June 2008. 
R. Persico, R. Bernini, Soldovieri F. (2005). The role of the measurement configuration in inverse scattering from buried objects under the Born approximation. IEEE Trans. Antennas and Propagation, Vol. 53, No.6, pp. 1875-1887.

Picozzi M., S. Parolai, M. Mucciarelli, C. Milkereit, D. Bindi, R. Ditommaso, M. Vona, M.R. Gallipoli, and J. Zschau. (2011). Interferometric Analysis of Strong Ground Motion for Structural Health Monitoring: The Example of the L'Aquila, Italy, Seismic Sequence of 2009. Bulletin of the Seismological Society of America, Vol. 101, No. 2, pp. 635-651, April 2011, DOI: 10.1785/0120100070.

Ponzo, F., Ditommaso, R., Auletta, G., Mossucca, A. (2010). A fast method for a structural health monitoring of Italian reinforced concrete strategic buildings. Bulletin of Earthquake Engineering. DOI: 10.1007/s10518-010-9194-6. Vol. 8, No. 6, pp. 14211434.

Ponzo F. C., Mossucca A., Di Cesare A., Nigro D., Dolce M., Moroni C. (2011). Seismic assessment of the $\mathrm{R} / \mathrm{C}$ buildings: the case study of Di.Coma.C Centre after the L'Aquila (Italy) 2009 seismic sequence. 9th Pacific Conference on Earthquake Engineering. Building an Earthquake-Resilient Society. 14-16 April, 2011, Auckland, New Zealand.

RILEM Recommendation NDT 1, Testing of Concrete by the Ultrasonic Pulse Method, Paris, December 1972.

Sasaky, Y. (1992). Resolution of resistivity tomography inferred from numerical simulation, Geophys. Prospect., Vol. 54, pp. 453-464.

A. Satriani, A. Loperte, M. Proto, and M. Bavusi (2011a). Building damage caused by tree roots: laboratory experiments of GPR and ERT survey. Adv. Geosci., Vol. 24, pp. 133-137.

Satriani A., A. Loperte, M. Proto (2011b). Electrical resistivity tomography for coastal salt water intrusion characterization along the Ionian coast of Basilicata Region (Southern Italy). Fifteenth International Water Technology Conference, IWTC-15 2011, Alexandria, Egypt, 28-30 May.

Scott M,. Rezaizadeha A., Delahazab A., Santosc C. G., Moored M., Graybeale B. and Washerf G. (2003). A comparison of nondestructive evaluation methods for bridge deck assessment. NDTEE Int., Vol., 36, pp. 245-55.

Seppänen A., Karhunen K., Lehikoinen A. \& Kaipio J.P., (2009). Electrical resistance tomography imaging of concrete. Concrete Repair, Rehabilitation and Retrofitting II pp. 571-577. Alexander et al (eds). (c) 2009 Taylor \& Francis Group, London, ISBN 978-0-415-46850-3

Shaari A., Millard S. G. and Bungeyb J. H. (2004). Modelling the propagation of a radar signal through concrete as a low-pass filter. NDTEE Int., Vol. 37, pp. 237-42.

Sharma, P.S. (1997). Enviromental and Engineering Geophysics. Cambridge University Press.

Shi B., Xu H., Chen B., Zhang D., Ding,Y., Cui H., Gao J.,(2003). Feasibility study on the application of fiber-optic distributed sensors for strain measurementin the Taiwan Strait Tunnel project. Marine Georesources and Geotechnology, Vol. 21, pp. 333-343. 
Shaw M. R., Millard S. G. Molyneauxc T. C. K., Taylord M. J., Bungeyb J. H. (2005). Location of steel reinforcement in concrete using ground penetrating radar and neural networks. NDTEE International, Vol. 38, pp. 203-212.

Soldovieri F. and Orlando L.(2009). Novel tomographic based approach and processing strategies for multi-frequency antennas GPR measurements using multi-frequency antennas. Journal of Cultural Heritage, Vol. 10, pp. e83-e92.

Soldovieri F., Solimene R., (2010). Ground Penetrating Radar Subsurface Imaging of Buried Objects, in Radar Technology, IN-TECH, Vienna Austria, ISBN 978-953-307-029-2, Edited by: Guy Kouemou, January 2010.

Stolt, R. H. (1978) Migration by Fourier Transform. Geophysics, Vol. 43 pp. 23-48.

Tsoflias G.P., Van Gestelz J.P., Blankenship D.D. and Sen M., (2004). Vertical fracture detection by ex-ploiting the polarization properties of ground-penetrating radar signals. Geophysics, Vol. 69, pp. 803-810.

UNI EN 12504-1 (2002) Prove sul calcestruzzo nelle strutture - Carote - Prelievo, esame e prova di compressione

UNI EN 12504-2 (2001) Prove sul calcestruzzo nelle strutture - Prove non distruttive Determinazione dell'indice sclerometrico

UNI EN 12504-3 (2005) Prove sul calcestruzzo nelle strutture - Parte 3: Determinazione della forza di estrazione

UNI EN 12504-4 (2005) Prove sul calcestruzzo nelle strutture - Parte 4: Determinazione della velocità di propagazione degli impulsi ultrasonici

Utsi V., Birtwisle A. and Coock J. (2008). Detection of subsurface reflective cracking using GPR. Structural Faults \& Repair-2008: 12th Int. Conf., Edinburgh, UK, 10-12 June 2008.

Wenzel H. and Pichler D. (2005). Ambient Vibration Monitoring. Wilhey.

Zou L., Bao X., Wan Y., Chen L., (2005). Coherent probe-pump-based Brillouin sensor for centimetre-crack detection. Opt. Let., Vol. 15, pp. 370-372. 


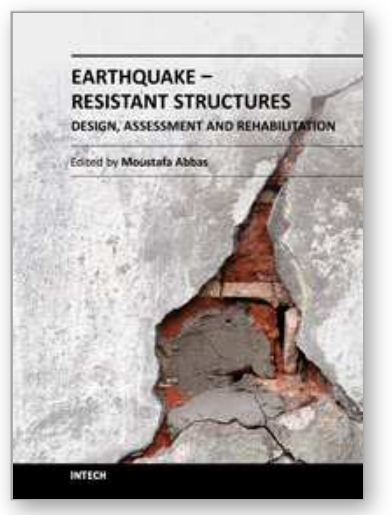

\section{Earthquake-Resistant Structures - Design, Assessment and Rehabilitation}

Edited by Prof. Abbas Moustafa

ISBN 978-953-51-0123-9

Hard cover, 524 pages

Publisher InTech

Published online 29, February, 2012

Published in print edition February, 2012

This book deals with earthquake-resistant structures, such as, buildings, bridges and liquid storage tanks. It contains twenty chapters covering several interesting research topics written by researchers and experts in the field of earthquake engineering. The book covers seismic-resistance design of masonry and reinforced concrete structures to be constructed as well as safety assessment, strengthening and rehabilitation of existing structures against earthquake loads. It also includes three chapters on electromagnetic sensing techniques for health assessment of structures, post earthquake assessment of steel buildings in fire environment and response of underground pipes to blast loads. The book provides the state-of-the-art on recent progress in earthquake-resistant structures. It should be useful to graduate students, researchers and practicing structural engineers.

\section{How to reference}

In order to correctly reference this scholarly work, feel free to copy and paste the following:

Massimo Bavusi, Romeo Bernini, Vincenzo Lapenna, Antonio Loperte, Francesco Soldovieri, Felice Carlo Ponzo, Antonio Di Cesare and Rocco Ditommaso (2012). Electromagnetic Sensing Techniques for NonDestructive Diagnosis of Civil Engineering Structures, Earthquake-Resistant Structures - Design, Assessment and Rehabilitation, Prof. Abbas Moustafa (Ed.), ISBN: 978-953-51-0123-9, InTech, Available from: http://www.intechopen.com/books/earthquake-resistant-structures-design-assessment-andrehabilitation/electromagnetic-sensing-techniques-for-civil-engineering-structures-non-destructive-diagnostics

\section{INTECH}

open science | open minds

\section{InTech Europe}

University Campus STeP Ri

Slavka Krautzeka 83/A

51000 Rijeka, Croatia

Phone: +385 (51) 770447

Fax: +385 (51) 686166

www.intechopen.com

\section{InTech China}

Unit 405, Office Block, Hotel Equatorial Shanghai

No.65, Yan An Road (West), Shanghai, 200040, China

中国上海市延安西路65号上海国际贵都大饭店办公楼 405 单元

Phone: +86-21-62489820

Fax: $+86-21-62489821$ 
(C) 2012 The Author(s). Licensee IntechOpen. This is an open access article distributed under the terms of the Creative Commons Attribution 3.0 License, which permits unrestricted use, distribution, and reproduction in any medium, provided the original work is properly cited. 